\title{
Re-Envisioning Addiction Therapy
}

\author{
Brian L Ackerman MD* \\ Psychiatrist \& Director of Mindfulness \& Meditation, USA
}

Submission: July 01, 2017; Published: July 05, 2017

*Corresponding author: Brian L Ackerman MD, Psychiatrist \& Director of Mindfulness \& Meditation, Services \& Training at the Kent Center, in Warwick, Rhode Island; Psychiatrist, Community Care Alliance, Woonsocket, RI where he runs Mindfulness Groups for Substance Users, Staff Psychiatrist East Bay CAP in E. Providence, and has a private practice in Providence, RI, USA, Email: ackermanpsychiatry@gmail.com

\section{Opinion}

The traditional 'medical model' of addiction is useful in some aspects of addiction assessment and treatment and rather confounding in other aspects. What I will present here is a new way of thinking about addiction treatment, in which the 'medical model' is primarily confined to only one aspect of substance treatment, namely the assessment and treatment of states of intoxication and withdrawal. However, at the more prevalent other stages of alcohol and substance treatment, i.e. when our patients are no longer intoxicated or are well beyond withdrawal, I propose that we use a different, non-medical model, more consistent with a characterological and psychospiritual assessment; dis-eased, for sure; but not disease or illness based. At these 'other stages' we might be better served to conceptualize the problems as more psychologically drivenobsessive-compulsive and self-injurious in nature, and less physiologically drug-dependency driven. When people obsess, what they obsess about is of interest for sure, but the fact that they are obsessing is what is most important.

While there are many reasons that compel substance users to use substances, the usual driving mechanism is that they cannot stand the anxious-depressed-bored-inpatient-irritable moods they have, and are too willing to seek a quick fix with little regard to the consequences. Many substance abusers far beyond the window of their intoxication, and withdrawal, go to their AA and NA meetings thinking of themselves as 'addicts' and many are on 'medications', to help manage the residual 'cravings' of their 'addiction'. Continuing to be labeled with this medical type diagnosis of addiction, further identifying with the diagnosis... 'I am an addict', and taking medications for their 'condition', I believe handcuffs users and providers alike to a limited way of thinking and ultimately obscures the picture of what is really going on and what needs to be done to remedy the problem.

I would suggest that these so called-'cravings' which persist or recur after the withdrawal period has clearly passed, are really more psychological, more akin to craving an ice cream cone and are really primarily a -desire on steroids, far removed from a nicotine type craving.
The battle waged between a person's desires and their capacity for restraint of those desires, then goes right to the heart of their characterological struggles. While thinking of themselves as 'addicts' with 'cravings, may help cut through the briar patch of their tendencies toward minimization and denial...i.e., at least they are admitting they have a problem, addiction terminology may actually be confusing them and helping them cop to the wrong plea, distracting them to seek pharmacological relief for their cravings, and failing to address their more primary issues of their impulsivity, their self-neglect, and their self-harming tendencies.

Many substance users will say flat out; that if the medicine we prescribe does not fix their anxiety and dysphoric moods, they will simply use again, without grasping that their very requirement for a chemical fix, whether that be self-or physician prescribed, is still a chemical fix demand. Their demand: 'I need a fix' is, in my view, pointing metaphorically to their greater psycho-spiritual state of 'brokenness' which it would seem would be more effectively addressed psycho-spiritually; not chemically. AA may have a level of success greater than other substance treatment programs do, because by having the availability of daily meetings, sponsors, and the invocation of higher powers, the program begins to address more directly user's feelings of helplessness, hopelessness, and worthlessness. It is these psycho-spiritual states of emptiness and brokenness that it seems users are trying to stuff out and distract or escape from with their drug usage. AA has become for many the Triple A.. who you call when you feel your humanity has broken down on the road of life, and you can no longer ride on your rims.

One area where the 'medical model' of addiction is widely accepted and utilized is in all stages of treatment of 'smoking'... nicotine addiction. A foreign chemical: Nicotine is introduced to the brain and tickles the fancy of some Dopamine reward pathway and within a relatively short period of time these folks become 'addicted' to the nicotine and when their nicotine blood level drops, they 'crave' a smoke. Medications like Chantrix are often useful to help curb their cravings and act in a manner similar to Cyboxin for moderating opioid cravings. One issue that 
continually confounds all heath care providers is how focused and determined smokers are to continue their smoking habits despite knowing full well, the rather horrific consequences for their health. The thinking here then becomes they must be 'addicted' or why else would they continue to smoke.

But this is circular reasoning, because what if the drive mechanism of their smoking is their underlying obsessionalcompulsive type impulses to self-injure, more akin to the Borderline's impulses to cut, and their smoking lost in the fog of addiction is simply the means they use to self-injure. I have written elsewhere to suggest redefining alcohol and substance use as forms of what I call a Self-Injurious Impulse Disorder (SIID) [1]. The chief focus here is that if the consequence of a person's behavior is self-injury whether they injure themselves by drugs, violence or crime, or smoking is secondary to a more primary problem of self -injurious impulses which, in my view, needs to become the primary focus of treatment.

Borderlines who characteristically self-injure by cutting are clearer examples of those who demonstrate a rather remarkable willingness to self-harm. But, we don't think that the Borderline is 'addicted' to cutting. While they often experience some relief from the cutting, it is typically a very temporary relief from their anxious-dysphoric mood states, soon to be followed by guilt for what they have done. Their cutting is the means to their temporary relief. Like the Borderline, the substance user has a mixture of impulses to self-injure; self-neglect and so too their drug use might be considered just a means to this self-injury.

Now when we return to nicotine addiction where we can readily acknowledge that the smoker is in fact at one level a nicotine addict, we return to wonder what role the self-injurious impulse drive mechanism is playing with nicotine addiction. It may be Self Injurious Impulse Disorder (SIID) which drives the addiction as much as the other way around. Is a smoker saying in effect, 'I am addicted to hurting and neglecting myself??' While self-injury and self-neglect may indeed become habit-like, similar to not making the bed, or always arriving late for appointments, the very idea of being 'addicted' to self-injury and self-neglect ought to create a cognitive-emotional dissonance for substance abuse users and treaters alike. I believe we would do better to challenge the thought pattern itself, 'Are you telling me you are addicted to hurting and neglecting yourself; really? rather than letting them off the hook and concluding it is all about addiction.

Borderlines who cut their wrists at least grasp that they are self-injuring when they cut. But substance users even those who are here but for the grace of God and Narcan, have a much more difficult time recognizing and accepting that their substance is as really a not particularly well-disguised form of self-injury. They generally prefer to operate on the illusion they with their substance use they are really just trying to help (not hurt themselves..simply seeking relief), and the whole idea of even thinking through the overall consequences of their actions are rather foreign to them-their impact on their bodies on their brains, their minds, their stomachs, their livers, never mind on others-spouses, partners, children, roommates, bosses, coworkers etc. who are completely off their radar screen. At the least, they are operating like J-walkers, knowing they should cross at the light and in the crosswalks but J-walk anyway. At other times, however, their utter disregard for the law, for rules, for limits of any kind is more sociopathic. They are willfully disregarding the consequences of their behavior. Knowing the consequences will be really bad for them; they do it anyway.

In a rather chilling documentary I watched on spousal abuse, they showed a husband who had beat up his wife in a state of drunkenness, and the wife said to her husband the next morning, 'I know you only did this because you were drunk!'; and he said to her in a way that still haunts me today. 'You just don't get it, do you? I did not beat you because I drank; I drank because I was going to beat you! The message of the documentary was clear; the driving mechanism was violence, and alcohol usage but a lubricant, an accessory to the fact. So too we need to consider that in so many instances of substance use the drive mechanism is a form of self-directed violence, and the drug usage the means to that end. Our posture as treatment providers is akin to that of the spouse of the violent husband. When we support the notion, 'You drank because you are addicted.' for the relapsing substance user, we miss the opportunity to hold the substance users selfharming feet to the fire.

What I am also proposing here, is a new way of thinking about substance use that considers most stages of it, primarily as a psychological syndrome, obsessive-compulsive, and impulsive in nature, that is driven by self-hatred. Since there is no pharmacological or chemical antidote to self-hatred, we need to help our patients accurately identify this core problem, and become more skilled ourselves as providers at helping our patients undergo a 'psychological root canal' to help them free themselves from this underlying self-hatred and the attendant self-injurious impulses.

Mindfulness is one such approach, as it teaches first the awareness of the self-hatred, and the self-injurious impulses, and then secondarily cultivates the true antidote which is their capacity for self-love, self-care, and self-protection which needs to be strengthened in order to restrain the impulses to selfharm. In the paradigm I use, all human beings are seen as dualnatured and experience a tug of war between their unhealthy and healthy sides, with the deck unfortunately stacked for the unhealthy side to win. Mindfulness, also teaches them how they begin to help their healthy side triumph over the unhealthy side. It starts with cultivating their awareness of their everyday negative thought and feeling patterns and the many ways they have become identified with this negativity. 'I feel bad.' does not have to mean 'I am bad.' Having the thought, 'I am a failure', does not mean 'I am a failure.' 
Mindfulness promotes a more holistic sense of themselves, so that they can identify the unhealthy parts in them without being identified with these parts, as they also learn to be more aware of and more identified with their healthier parts. They learn to cultivate a greater awareness of their inner lives, and learn to think of themselves as mental gardeners, becoming increasing more proficient at tending to their mental garden, identifying more accurately what is weed that needs to be pulled, so that their healthier side cans truly grow [2].

The folks who are most successful in this program learn not to think of themselves as 'addicts', but as people struggling to get a better grip on the rope that represents the tug of war between their healthy and unhealthy sides, and with this better grip to use their energy more effectively to free themselves from their negativity and impatience, and direct their psychological energy, their thoughts, feelings, decisions, and actions toward their goals of their health and well-being.

\section{References}

1. Brian L Ackerman (2017) Moving Beyond an Addiction Model of Alcohol and Substance Abuse: A Mindfulness Perspective. Journal of Alcoholism \& Drug Dependence.

2. Brian L Ackerman (2017) Treatment of Alcohol and Substance Dependence: An Introduction to a Mindfulness Based Approach to Assessment and Treatment. Journal of Substance Abuse \& Alcoholism.

\section{Your next submission with Juniper Publishers will reach you the below assets}

- Quality Editorial service

- Swift Peer Review

- Reprints availability

- E-prints Service

- Manuscript Podcast for convenient understanding

- Global attainment for your research

- Manuscript accessibility in different formats ( Pdf, E-pub, Full Text, Audio)

- Unceasing customer service

Track the below URL for one-step submission https://juniperpublishers.com/online-submission.php 